Georgia State University

ScholarWorks @ Georgia State University

2010

\title{
Mindfulness mediates the relation between disordered eating- related cognitions and psychological distress
}

Akihiko Masuda

Georgia State University, amasuda@gsu.edu

J. W. Wendell

Follow this and additional works at: https://scholarworks.gsu.edu/psych_facpub

Part of the Psychology Commons

\section{Recommended Citation}

Masuda, Akihiko and Wendell, J. W., "Mindfulness mediates the relation between disordered eatingrelated cognitions and psychological distress" (2010). Psychology Faculty Publications. 95.

https://scholarworks.gsu.edu/psych_facpub/95

This Article is brought to you for free and open access by the Department of Psychology at ScholarWorks @ Georgia State University. It has been accepted for inclusion in Psychology Faculty Publications by an authorized administrator of ScholarWorks @ Georgia State University. For more information, please contact scholarworks@gsu.edu. 
Running head: DISORDERED EATING-RELATED COGNITIONS

Mindfulness Mediates the Relation between Disordered Eating-Related Cognitions and Psychological Distress

Akihiko Masuda,* \& Johanna W. Wendell

Georgia State University

*Corresponding author at: Department of Psychology, Georgia State University

Atlanta, GA 30303, USA.

Tel.: +1 (404) 413-6298

Fax: +1 (404) 413-6207.

Email Address: psyaxm@langate.gsu.edu 


\begin{abstract}
The present study investigated whether mindfulness mediates the relation between disordered eating-related cognitions and negative psychological outcomes within a nonclinical college sample. Disordered eating-related cognitions were positively associated with general psychological ill-health and emotional distress in interpersonal contexts and inversely related to mindfulness. Mindfulness, which was also inversely related to general psychological ill- health and emotional distress, was found to partially mediate the relations between disordered eating-related cognitions and the two predicted variables.
\end{abstract}

Key Words: disordered eating-related cognitions; psychological distress, mindfulness. 


\section{Introduction}

People in Western society generally endorse disordered eating-related cognitions. These cognitions include, but are not limited to, perceived importance of having an ideal weight and shape as a means of achieving self-acceptance, self-control over diet and weight, and acceptance by others (Cooper, Cohen-Tovee, Todd, Wells, \& Tovee, 1997; Fairburn, 2008; Mizes et al., 2000). In both clinical and non-clinical samples, research has shown that these cognitions are associated not only with symptoms of eating disorders (EDs), but also with negative psychological outcomes non-specific to EDs, such as functional impairment and general psychological ill-health (Bohn et al., 2008; Masuda, Price, Anderson, \& Wendell, 2010; Stice, Killen, Hayward, \& Taylor, 1998).

Recent literature seems to suggest that disordered eating-related cognitions do not necessarily lead to greater psychological distress, however (e.g., Brannan \& Petrie, 2008). For example, mindfulness-based cognitive behavior therapies, such as MindfulnessBased Cognitive Therapy (MBCT; Segal, Teasdale, \& Williams, 2004), state that psychological distress is attributed mainly to a maladaptive way of experiencing or responding to the negative cognitions and associated events. According to these interventions, when "negative” thoughts and feelings are experienced non-judgmentally as mental events, rather than as the absolute truth of one's life, maladaptive and avoidance-based coping strategies, which often exacerbate psychological distress further, are unlikely to occur.

\subsection{Mindfulness}

The construct of mindfulness seems particularly relevant in the present research context. Mindfulness has become one of the most widely studied topics in clinical 
psychology over the past several years because of its link to greater psychological health (e.g., Baer, 2006). Although the conceptualization of mindfulness varies among researchers and practitioners, it is often defined as a process of enhanced attention to and nonjudgmental awareness of present moment experience (Brown \& Ryan, 2003).

Research shows that mindfulness, when conceptualized in this way, is inversely related to a wide range of negative psychological outcomes, including depression and anxiety (Brown \& Ryan, 2003), general psychological distress (Baer, Smith, Hopkins, Krietemeyer, \& Toney, 2006), and emotional distress in stressful interpersonal contexts (Beitel, Ferrer, \& Cecero, 2005). Additionally, evidence seems to suggest a possible inverse link between mindfulness and disordered eating-related cognitions (Lavender, Jardin, \& Anderson, 2009). Furthermore, a study suggests that mindfulness may potentially mediate the link between disordered eating-related cognitions and psychological distress (Masuda et al., 2010).

\subsection{Present Study}

The purpose of the present study was to investigate whether mindfulness mediates the link between disordered eating-related cognitions and negative psychological outcomes. One of the predicted variables was general psychological ill-health, a good indicator of general psychopathology (e.g., Bond \& Bunce, 2000). The other variable was emotional distress in stressful interpersonal situations. This variable was selected because issues around disordered-eating spectrum concerns are often stressful and interpersonal in nature (Fairburn, 2008). Given existing literature (e.g., Masuda et al., 2010), it was hypothesized that mindfulness at least partially mediates the link between conviction of disordered eating-related cognitions and the two predicted variables. 


\section{Method}

\subsection{Participants}

Participants for the study were undergraduate psychology students from a large, public 4-year university in Georgia. The students were recruited through the university's online research participant pool. The sample for the current study consisted of 91 female participants who met the criteria for elevated disordered eating symptoms (i.e., scores on the EAT-26 $\geq 20$ ). The ages of participants ranged from 18 to 43 years, with an average age of $21.32(S D=4.97)$. Participants for the study were ethnically diverse, with $37 \%$ ( $n$ $=34)$ identifying as European American, 24\% $(n=22)$ as African American, 18\% $(n=$ 16) as Asian American/Pacific Islander, 6\% $(n=5)$ as Hispanic American, 14\% $(n=13)$ as biracial or "other”, and one individual identifying as Native American. Participants were also asked to identify their socioeconomic status. Three percent $(n=3)$ identified themselves as poor, 29\% $(n=26)$ as working class, 39\% $(n=35)$ as middle class, $29 \%(n$ = 26) as upper middle class, and one participant as upper class.

Body Mass Index (BMI) scores were calculated using participants’ self-report of height and weight (weight (lb) / [height (in) ${ }^{2}$ x 703). The standard weight status categories associated with BMI are “underweight” (BMI< 18.5), “normal” (BMI between 18.5 and 24.9), “overweight” (BMI between 25 and 29.9) and "obese” (BMI > 30.0) (Centers for Disease Control and Prevention, Division of Nutrition, Physical Activity and Obesity, 2011). BMI scores for the sample ranged from 15 to $39(M=23.87, S D=4.51)$. Seven percent $(n=6)$ of participants were qualified as being underweight, $59 \%(n=54)$ normal, 26\% $(n=24)$ overweight $(25<\operatorname{BMI}<29.9)$, and $8 \%(n=7)$ obese $(\mathrm{BMI} \geq 30)$.

\subsection{Measures}


The following measures were used to assess disordered eating-related cognitions, mindfulness, general psychological ill-health, and emotional distress in interpersonal settings.

\subsubsection{Disordered Eating Related Cognitions}

The Mizes Anorectic Cognitions Questionnaire-Revised (MAC-R; Mizes et al., 2000) is a 24-item self-report questionnaire designed to assess distorted cognitions related to all eating disorders. These cognitions are the fear of weight gain (e.g., "If I don’t establish a daily routine, everything will be chaotic, and I won't accomplish anything”), the importance of being thin or attractive to be socially accepted ("No one likes fat people; therefore, I must remain thin to be liked by others”), and self-esteem based on controlled eating habits and weight gain ("If my weight goes up, my self-esteem goes down”). Each item is scored on a 5-point Likert scale, ranging from 1 (strongly

disagree) to 5 (strongly agree), with a total score derived from the sum of all responses. Total scores range from 24 to 120, with higher scores indicating greater disordered eating-related cognitions. In a previous study with clinical samples of various eating disorders (Mizes et al., 2000), an alpha coefficient for the MAC-R total was .90.

\subsubsection{Mindfulness}

The Mindful Attention Awareness Scale (MAAS; Brown \& Ryan, 2003) is a 15item, self-report measure, which is designed to assess the frequency of mindlessness, the opposite of the construct of mindfulness, over time (e.g., "It seems I am running automatic without much awareness of what I'm doing”). Participants rate the degree to which they function mindlessly in daily life, using a six-point Likert scale ranging from 1 (almost always) to 6 (almost never). Total scores range from 15 to 90, with higher scores 
denoting greater mindfulness. The MAAS has good internal consistency (i.e., Cronbach’s ), ranging from .82 to .87 (Brown \& Ryan, 2003).

\subsubsection{General Psychological Ill-health}

The General Health Questionnaire-12 (GHQ-12; Goldberg, 1978) is a 12-item measure of overall general psychological ill-health. Using a 4-point Likert-scale format, (Banks et al., 1980), participants rate the frequency of behavioral and psychological stressors, ranging from 0 (not at all) to 3 (much more than usual). The total score is derived from the sum of all responses, ranging from 0 to 36, with higher scores indicating greater psychological ill-health. A recent study with a non-clinical college sample has shown an adequate internal consistency of the measure (Cronbach’s $\alpha=.87$; Masuda, Price, Anderson, Schmertz, \& Calamaras, 2009).

\subsubsection{Emotional Distress in Stressful Interpersonal and Emergency Situations.}

The Interpersonal Reactivity Index - Personal Distress (IRI-PD; Davis, 1983) is a 7-item subscale that measures feelings of personal anxiety and uneasiness during tense interpersonal contexts on a 5-point scale, ranging from 0 (does not describe me well) to 4 (describes me very well). Total scores are derived from the sum of all responses, ranging from 0 to 28, with higher scores indicating greater emotional distress. A recent study with a non-clinical college sample revealed that the subscale has satisfactory internal consistency (Cronbach’s $\alpha=.75$; Masuda et al., 2009).

\subsection{Procedure}

Participants who enrolled in the study were asked to complete an anonymous web-based survey. Participants voluntarily provided demographic information and completed the measures. 


\section{Results}

Prior to data analyses, gender was examined as a potential moderator of the relations among disordered eating-related cognitions, mindfulness, and negative psychological outcomes. Results failed to reveal gender as a moderating variable, however. For this reason, gender was omitted from the analyses. Descriptive statistics and correlations among the variables are shown in Table 1. Disordered eating-related cognitions were positively related to general psychological ill-health and emotional distress in stressful interpersonal contexts and negatively related to mindfulness. Mindfulness was negatively related to general psychological ill-health and emotional distress in stressful interpersonal contexts.

\subsection{Mindfulness as a Mediator of the relation between Disordered Eating-Related}

Cognitions and Emotional Distress and General Psychological Ill-Health.

Based on the guidelines of Baron and Kenny (1986), linear regression analyses were conducted to examine whether mindfulness mediates the relation between disordered eating-related cognitions and two dependent variables, emotional distress in stressful and interpersonal settings and general psychological ill-health. As shown in Table 1, the previously discussed correlations established a significant A path, between disordered eating-related cognitions and mindfulness, and a significant B path, between mindfulness and both dependent variables. Table 2 displays the results of the final step of the test of mediation. Results revealed that mindfulness partially mediated the relation between disordered eating-related cognitions and emotional distress in stressful interpersonal settings (initial $\beta=.24$, final $\beta=.18$ ) and the relation between disordered eating-related cognitions and general psychological ill-health (initial $\beta=.35$, final $\beta$ 
$=.25)$. The conservative Sobel tests of mediation suggested that mindfulness partially accounted for the relations between disordered eating-related cognitions and the two dependent variables.

\section{Discussion}

The present study revealed that both disordered eating-related cognitions and mindfulness were predictors of general psychological ill-health and emotional distress in stressful interpersonal contexts. Whereas disordered eating-related cognitions were positively and significantly related to these negative psychological outcomes, mindfulness was inversely related to them. There was an inverse relationship between disordered eating-related cognitions and mindfulness. Furthermore, mindfulness was found to partially mediate the relations between disordered eating-related cognitions and the negative psychological outcomes of interest.

Conceptually, the present study suggests that mindfulness plays an important role in the relations between disordered eating-related cognitions and poor psychological outcomes. Clinically, the study suggests that it may be beneficial to assess the degree to which an individual experiences internal and external events nonjudgementally as they are in understanding and promoting psychological wellbeing. This position concurs with mindfulness-based interventions, which are shown to be effective for disordered eating spectrum problems and related issues (e.g., Baer, Fischer, \& Huss, 2005; Heffner \&

Eifert, 2004; Safer, Telch, \& Agras, 2001; Telch, Agras, \& Linehan, 2001). As discussed elsewhere (Lavender et al., 2009), the present study seems to support the potential values of mindfulness-based interventions and suggests that mindfulness may be a potential process of change in these methods. 
The present investigation has several notable weaknesses. The study is theoretical; therefore, it should not be treated as a report on ED-related psychopathology or psychopathology in general. The study is also limited in scope in part because it did not include other factors, such as neuroticism (Tylka, 2004), emotion dysregulation (Lavender \& Anderson, 2010), social perfectionism (Brannan \& Petrie, 2008; Tylka, 2004), and ED-specific psychiatric symptoms (Bohn et al., 2008), that may account for the link between disordered eating-related cognitions and non-specific negative psychological outcomes.

Additionally, the present research participants were limited to non-clinical college undergraduates. Although negative behavioral outcomes related to disordered eatingrelated cognitions seem pervasive among this group (e.g., Vohs, Heatherton, \& Herrin, 2001), it is important to replicate the present findings in clinical samples with and/or without EDs. The exclusive reliance on self-report measures is yet another limitation. Finally, perhaps the largest limitation was the reliance on a cross-sectional and correlational design. The analytic strategy of the present study did not elucidate any causal inferences or functional link among the variables of interest.

Despite these limitations, the present study provides additional evidence in regard to the associations among disordered eating-related cognitions, mindfulness, and negative psychological outcomes. The study also suggests that mindfulness is a useful concept in understanding and perhaps promoting behavioral health in the context of disordered eating-related cognitions. 


\section{References}

Baer, R. A. (Eds.). (2006). Mindfulness-based treatment approaches: Clinician's guide to evidence base and applications. New York: Academic Press.

Baer, R. A., Fischer, S., \& Huss, D. B. (2005). Mindfulness and acceptance in the treatment of disordered eating. Journal of Rational-Emotive \& CognitiveBehavior Therapy, 23, 281-300.

Baer, R. A., Smith, G. T., Hopkins, J., Krietemeyer, J., \& Toney, L. (2006). Using selfreport assessment methods to explore facts of mindfulness. Assessment, 13, 27-45.

Banks, M. H., Clegg, C. W., Jackson, P. R., Kemp, N. J., Stafford, E. M., \& Wall, T. D. (1980). The use of the General Health Questionnaire as an indicator of mental health in occupational studies. Journal of Occupational Psychology, 53, 187-194.

Baron, R. M., \& Kenny, D. A. (1986). The moderator-mediator variable distinction in social psychological research: Conceptual, strategic, and statistic considerations. Journal of Personality and Social Psychology, 51, 1173-1182.

Beitel, M., Ferrer, E., \& Cecero, J. J. (2005). Psychological mindedness and awareness of self and others. Journal of Clinical Psychology, 61, 739-750.

Bohn, K., Doll, H. A., Cooper, Z., O’Connor, M., Palmer, R. L., \& Fairburn, C. G. (2008). The measurement of impairment due to eating disorder psychopathology. Behaviour Research and Therapy, 46, 1105-1110.

Bond, F. W., \& Bunce, D. (2000). Mediators of change in emotion-focused and problemfocused worksite stress management interventions. Journal of Occupational Health Psychology, 5, 156-163. 
Brannan, M. E., \& Petrie, T. A. (2008). Moderators of the body dissatisfaction-Eating disorder symptomatology relationship: Replication and Extension. Journal of Counseling Psychology, 55, 263-275.

Brown, K. W., \& Ryan, R. M. (2003). The benefits of being present: Mindfulness and its role in psychological well-being. Journal of Personality and Social Psychology, 84, 822-848.

Cooper, M., Cohen-Tovee, E., Todd, G., Wells, A., \& Tovee, M. (1997). The eating disorder belief questionnaire: Preliminary development. Behaviour Research and Therapy, 35, 381-388.

Davis, M. H. (1983). Measuring individual differences in empathy: Evidence for a multidimensional approach. Journal of Personality and Social Psychology, 44, 113-126.

Fairburn, C. G. (Eds.). (2008). Cognitive behavior therapy and eating disorders. New York: The Guilford Press.

Goldberg, D. (1978). Manual of the general health questionnaire. Windsor: National Foundation for Educational Research.

Heffner, M., \& Eifert, G. H. (2004). The anorexia workbook: How to accept yourself, heal suffering, and reclaim your life. Oakland, CA: New Harbinger Publications.

Lavender, J. M., Jardin, B. F., \& Anderson, D. A. (2009). Bulimic symptoms in undergraduate men and women: Contributions of mindfulness and thought suppression. Eating Behaviors, 10, 228-231. 
Lavender, J. M., \& Anderson, D. A. (2010). Contribution of emotion regulation difficulties to disordered eating and body dissatisfaction in college men. International Journal of Eating Disorders, 43, 352-357.

Masuda, A., Price, M., Anderson, P. L., Schmertz, S. K., \& Calamaras, M. R. (2009). The role of psychological flexibility in mental health stigma and psychological distress for the stigmatizer. Journal of Social and Clinical Psychology, 28, 1244-1262.

Masuda, A., Price, M., Anderson, P. L., \& Wendell, J. W. (2010). Disordered eatingrelated cognition and psychological flexibility as predictors of psychological health among college students. Behavior Modification, 34, 3-15.

Mizes, J. S., Christiano, B., Madison, J., Post, G, Seime, R., Varnado, P. (2000). Development of the Mizes Anorectic Cognitions Questionnaire-Revised: Psychometric properties and factor structure in a large sample of eating disorder patients. International Journal of Eating Disorder, 28, 415-421.

Safer, D. L., Telch, C. F., \& Agras, W. S. (2001). Dialectical behavior therapy for bulimia nervosa. American Journal of Psychiatry, 158, 632-634.

Segal, Z. V., Teasdale, J. D., \& Williams, J. M. G. (2004). Mindfulness-based cognitive therapy: Theoretical rationale and empirical status. In S. C. Hayes, V. M. Follette, \& M. M. Linehan (Eds.), Mindfulness and acceptance: Expanding the cognitive behavioral tradition (pp. 45-65). New York: Guilford Press.

Stice, E., Killen, J. D., Hayward, C., \& Taylor, C. B. (1998). Support for the continuity hypothesis of bulimic pathology. Journal of Consulting and Clinical Psychology, $66,784-790$. 
Telch, C. F., Agras, W. S., \& Linehan, M. M. (2001). Dialectical behavior therapy for binge eating disorder. Journal of Consulting and Clinical Psychology, 69, 10611065.

Tylka, T. L. (2004). The relation between body dissatisfaction and eating disorder symptomatology: An analysis of moderating variables. Journal of Counseling Psychology, 51, 178-191.

Vohs, K. D., Heatherton, T. F., \& Herrin, M. (2001). Disordered eating and the transition to college: A prospective study. International Journal of Eating Disorders, 29, 280-288. 
Table 1

Means, Standard Deviations, Coefficient Alphas, and Zero-Order Relations between all Variables

\begin{tabular}{lrrrr} 
& 1 & 2 & 3 & 4 \\
\hline 1. Disordered Eating Related Cognitions (MAC-R) & -- & $-.31^{*}$ & $.35^{*}$ & $.24^{*}$ \\
2. Mindfulness (MAAS) & & -- & $-.38^{*}$ & $-.26^{*}$ \\
3. General Psychological Ill-Health (GHQ-12) & & & -- & $.26^{*}$ \\
4. Emotional Distress (IRI-PD) & & & & -- \\
$M$ & 58.45 & 58.45 & 12.60 & 12.65 \\
$S D$ & 15.23 & 12.55 & 6.63 & 4.84 \\
$\alpha$ & .90 & .89 & .89 & .75 \\
\hline
\end{tabular}

Note. $N=625,{ }^{*} p<.01$. MAC-R $=$ Mizes Anorectic Cognitions Questionnaire-Revised, MAAS = Mindful Attention and Awareness Scale, GHQ = General Health Questionnaire, IRI-PD = Interpersonal Reactivity Index-Personal Distress. 
Table 2

Linear Regression Analysis for Testing the Final Step of Mindfulness as Mediator

\begin{tabular}{|c|c|c|c|c|c|}
\hline Variables & $\beta$ & $B$ & $S E B$ & $t$ & Sobel z \\
\hline \multicolumn{6}{|l|}{ Emotional Distress (IRI-PD) } \\
\hline Disordered Eating-related Cognitions (MAC-R) & $.18^{*}$ & .06 & .01 & 4.47 & \\
\hline Mindfulness (MAAS) & $-.20 *$ & -.08 & .02 & -5.10 & $5.16^{*}$ \\
\hline \multicolumn{6}{|l|}{ General Psychological Ill-Health (GHQ-12) } \\
\hline Disordered Eating-related Cognitions (MAC-R) & $.25 *$ & .11 & .02 & 6.75 & \\
\hline Mindfulness (MAAS) & $-.30 *$ & -.16 & .02 & -7.97 & $6.32 *$ \\
\hline
\end{tabular}

Note. $N=625,{ }^{*} p<.01$. IRI-PD = Interpersonal Reactivity Index-Personal Distress, MAC-R = Mizes Anorectic Cognitions Questionnaire-Revised, MAAS = Mindful Attention and Awareness Scale, GHQ = General Health Questionnaire. 